\title{
Análisis de anomalías geobotánicas a partir del procesamiento e interpretación de productos de sensores remotos, estudio de caso: occidente de Boyacá (Colombia)
}

\author{
Analysis of geobotanical anomalies from the processing \\ and interpretation of remote sensing products: Case study \\ of West Boyacá (Colombia)
}

\author{
Manuel Guillermo Zafra Dulcey ${ }^{1}$ \\ *Email de correspondencia: manuelzafra@landterra.com.co \\ Recibido: 28 de mayo de 2018 \\ Aceptado: 18 de diciembre de 2018 \\ Publicado en línea: 15 de julio de 2019 \\ Doi: 10.32685/0120-1425/boletingeo.45.2019.485
}

Citación: Zafra D., M. G. (2019). Análisis de anomalías geobotánicas a partir del procesamiento e interpretación de productos de sensores remotos, estudio de caso: occidente de Boyacá (Colombia). Boletín Geológico, 45, 23-35. Doi: https://doi.org/10.32685/0120-1425/boletingeo.45.2019.485

\section{RESUMEN}

Este trabajo presenta la delimitación de una nueva zona de interés para la exploración detallada de esmeraldas en Colombia mediante la interpretación de anomalías geobotánicas en zonas de cobertura vegetal densa. Se diseñó una metodología en la que se calcularon quince índices vegetales, de los cuales se seleccionaron aquellos cuyas anomalías presentan mayor correlación con los lineamientos detectados, mediante la interpretación del modelo de sombras generado a partir el modelo digital de terreno (MDT). Un análisis espectral adelantado en las zonas mineralizadas del área de mayor correlación arrojó una aureola de estrés de vegetación en todos los casos estudiados y corroboró una relación directa entre la albitización presente en las zonas mineralizadas, los lineamientos y los niveles de estrés vegetal. Se identificó como objetivo de exploración detallada un sector localizado entre la mina de Coscuez y la mina La Pita, donde los índices de vegetación son más favorables y se correlacionan mejor con los lineamientos naturales del terreno. Se comprobó que la metodología planteada de anomalías geobotánicas es coherente y puede ser empleada como herramienta de exploración esmeraldífera.

Palabras clave: índices de vegetación, anomalías geobotánicas, análisis espectral, esmeralda, sensores remotos.

Consultor de Landaterra Consultores. 


\begin{abstract}
T
This work presents the boundaries of a new area of interest for the detailed exploration of emeralds in Colombia, identified through the interpretation of geobotanical anomalies in areas of dense vegetation. A methodology was designed in which fifteen vegetation indices were calculated. The anomalies correlated most with the lineaments detected from the interpretation of a shaded-relief model generated from a digital terrain model (DTM) were selected. A detailed spectral analysis in the mineralized zones of the area with the highest correlation showed a halo of vegetative stress in all studied cases; moreover, the analysis corroborated a direct relationship between the albitization present in the mineralized zones, the lineaments and the degree of vegetative stress. A sector between the Coscuez mine and the La Pita mine was identified as a target for detailed exploration, where the vegetation indexes indicate less vegetative stress and correlate better with the natural terrain lineaments. It was found that the proposed methodology based on geobotanical anomalies yields consistent results and can be used as a tool for emerald exploration.
\end{abstract}

Keywords: Vegetation indices, geobotanical anomalies, spectral analysis, emerald, remote sensing.

\section{INTRODUCCIÓN}

olombia es un país con un desarrollo básico en ex- ploración minera: las dificultades de orden social, económico y tecnológico han relegado a la minería, como en el caso concreto de las esmeraldas, a un retraso en las técnicas exploratorias. Se plantean técnicas de utilización de sensores remotos como un método efectivo y de bajo costo para delimitar zonas nuevas en explotación de recursos minerales. Las dificultades del terreno, por su abundante cobertura vegetal y complicada accesibilidad, no permiten realizar campañas exploratorias detalladas que concreten ese objetivo.

Con menos de un $15 \%$ del territorio nacional estudiado para minería, Colombia se considera un país inmaduro en términos exploratorios. Esta condición, sumada a las manifestaciones minerales y los precios altos, ha motivado a nacionales y extranjeros a buscar nuevas oportunidades que en algunos casos son esencialmente mineras y en otros sólo objeto de especulación. (Unidad de Planeación Minero-Energética, 2014).

Desde el punto de vista investigativo, en la exploración de recursos minerales se usan índices vegetales principalmente en depósitos asociados a pórfidos cupríferos, mineralizaciones de oro y otros metales, median- te la interpretación de imágenes satelitales de anomalías geoquímicas, esencialmente seritización y argilización. Camacho Velasco (2015) realiza una evaluación de la técnica del análisis de imágenes hiperespectrales (HSI) y su aplicación, uso actual y futuro, que se ha restringido al uso privado en la búsqueda de oro y minerales metálicos por AngloGold Ashanti, Ecopetrol y la Agencia Nacional de Hidrocarburos, a nivel estatal. Crosta (1989) y Van der Meer (2006) han realizado estudios de la respuesta espectral de diferentes minerales asociados a depósitos epitermales y las alteraciones relacionadas con los mismos.

Los yacimientos de esmeralda en Colombia, a diferencia de los de otros países, se emplazan en lutitas oscuras carbonosas, en zonas con alteración propilítica y albitización. La alta presencia anómala de $\mathrm{Na}$ y $\mathrm{Cr}$ en la roca encajante, el primero por alteración hidrotermal y el segundo como oligoelemento presente en la lutita negra carbonosa de la formación Muzo, puede generar una salinidad del suelo en las zonas alteradas y verse expresado en la salud o estrés de la vegetación. Este principio básico plantea, en primera instancia, la necesidad de determinar una relación posible entre los índices de vegetación, las características geológicas del área de trabajo y las mineralizaciones de esmeraldas, para priorizar áreas nuevas de exploración.

Debido a que la albitización y propilitización son los tipos de alteración presentes en la zona de estudio, el diseño de una metodología de trabajo que permita la 
delimitación de zonas bajo parámetros corroborables es un ejercicio inédito para la industria de las esmeraldas en Colombia.

Basado en esta premisa, el objetivo de este trabajo es la evaluación de diferentes índices de vegetación con miras a identificar zonas en las que la absorción o reflectividad captada por el sensor sea anómala, para de este modo poder establecer su relación directa con los condicionantes litológicos, estructurales y geoquímicos que limitan la precipitación de las esmeraldas en Colombia, de tal manera que las anomalías geobotánicas identificadas sean un indicador de zonas con alteración.

\subsection{Anomalía geobotánica}

Se establece como la interacción de las características físico-químicas intrínsecas del tipo de cobertura vegetal de un área y los condicionantes de cantidad y calidad de biomasa presente (figura 1) (Biology Dictionary, 2017). Existe una fuerte interrelación entre estas variables y las características del suelo que las soporta; de igual manera, las propiedades del suelo son una respuesta al regolito que las genera.

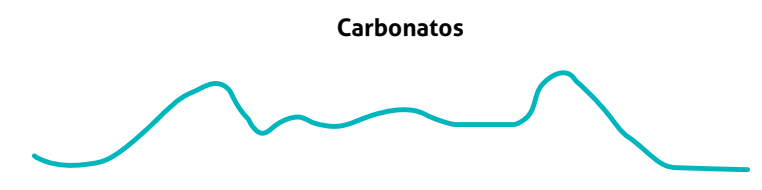

Radiométricas

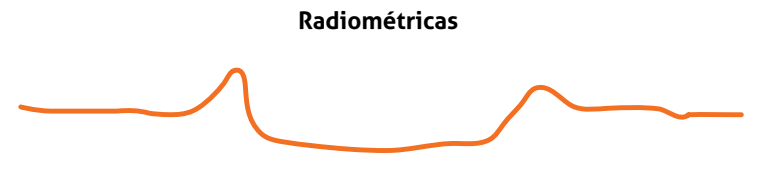

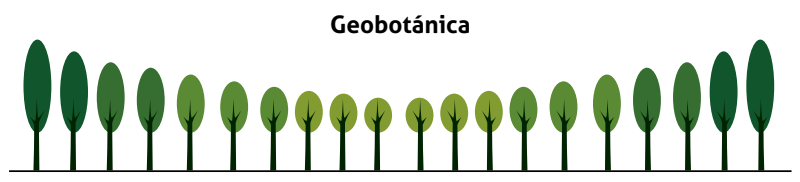

Figura 1. Anomalías asociadas a alteraciones superficiales. Fuente: modificado a partir de Souza Filho et al. (2008)

Souza Filho et al. (2008) realizó una evaluación de las alteraciones superficiales inducidas por hidrocarburos y su detección por técnicas de percepción remota, en la que la variación de la química del suelo aparecía direc- tamente relacionada con la presencia de etano, pentano, propano y metano. Por otra parte, Singer (2015) evaluó la correlación que existe entre las diferencias de $\mathrm{pH}$, Eh y la movilidad de elementos, así como las repercusiones en la calidad y cantidad de la vegetación que circunda dicha alteración.

Los factores que influyen en la movilización de metales pesados en el suelo son características del suelo: $\mathrm{pH}$, potencial redox, composición iónica de la solución del suelo, capacidad de intercambio (catiónico y/o aniónico), presencia de carbonatos, materia orgánica, textura, entre otras. La naturaleza de la contaminación y el origen de los metales y formas de deposición y condiciones medioambientales producen acidificación, cambios en las condiciones redox, variación de temperatura y humedad en los suelos. (Sahuquillo, Rigol y Rauret, 2003).

\subsection{Indices de vegetación}

"Los índices de vegetación obtenidos a partir de sensores remotos son algoritmos para evaluaciones cuantitativas y cualitativas de la cobertura vegetal, el vigor y la dinámica de crecimiento, entre otras aplicaciones" (Xue y Su, 2017).

Los índices de vegetación se aplican en análisis cualitativos o cuantitativos. Empleados cualitativamente, permiten determinar rápidamente el estado relativo de la vegetación en una zona. Como una gran variedad de factores afecta directamente la producción de biomasa. Los índices pueden emplearse para determinar la influencia de dichos factores en una zona o momento. (Towers y von Martini, 2002)

\subsection{Firmas espectrales}

La radiación fotosintéticamente activa (RAP, casi el 28\% de la energía absorbida por la planta) es usada en la fotosíntesis y para la conversión de compuestos orgánicos de alta energía.

Las propiedades ópticas de las hojas en la región RAP dependen de varios factores, tales como condiciones de la radiación, especie vegetal, espesor de las hojas, estructura de la superficie de la hoja, clorofila, contenido de carotenoides de las hojas (pigmentos orgánicos que se encuentran en forma natural en las plantas), contenido 


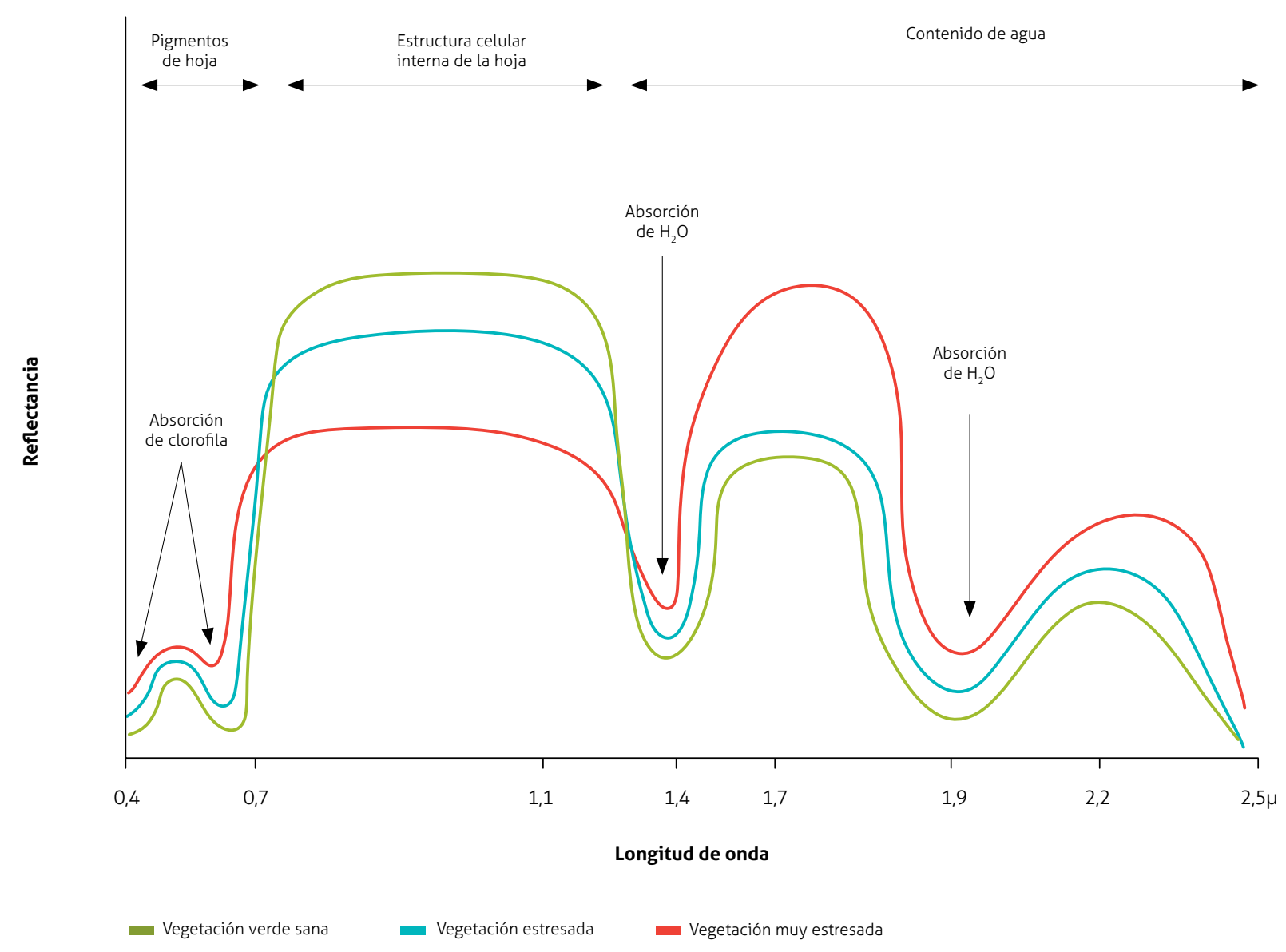

Figura 2. Comparación de las curvas espectrales de vegetación sana y estresada (diagrama esquemático).

Fuente: modificado a partir de Souza Filho et al. (2008)

de materia seca por unidad de área y estructura interna (Ross, 1981). De tal manera, es posible interpretar la "salud" de la planta a partir de la reflectancia calculada de cada pixel analizado (Milgrom, 1997) (figura 2). El comportamiento resultante de la firma espectral depende del estado de estrés o salud de la planta, y este a su vez está directamente relacionado con las condiciones físico-químicas del suelo, como emplazamiento de la misma (Prieto, 2009); (Heldt, 1997).

\subsection{Geología de las mineralizaciones de esmeraldas en Colombia}

Se pueden considerar tres aspectos clave para la precipitación de las esmeraldas: los condicionantes litológicos, estructurales y geoquímicos en un contexto de temperatura y presión adecuado. Estos aspectos se constituyen en el objetivo de exploración necesario para descubrir nuevas zonas o para potenciar aquellas ya conocidas en el negocio minero esmeraldífero.

La mineralización de esmeraldas en el cinturón esmeraldífero occidental de Colombia está restringida a la relación de fluidos de origen hidrotermal y neumatolítico en conjunción con rocas sedimentarias cretácicas pertenecientes a la formación Muzo, de edad hauteriviense-barremianse (Mendoza Parada, 1996), constituidas por intercalaciones de lutitas negras carbonosas laminadas y lenticulares con lutitas silíceas y bandas arenosas y calcáreas (figura 3).

Los fluidos hidrotermales vetiformes presentan una paragénesis mineral que incluye calcita, pirita, cuarzo y esmeralda. Localmente pueden presentar carbonatos de tierras raras como parisita y codazzita.

Es conocido que la presencia de esmeraldas en el occidente de Boyacá está restringida a la formación Muzo. 


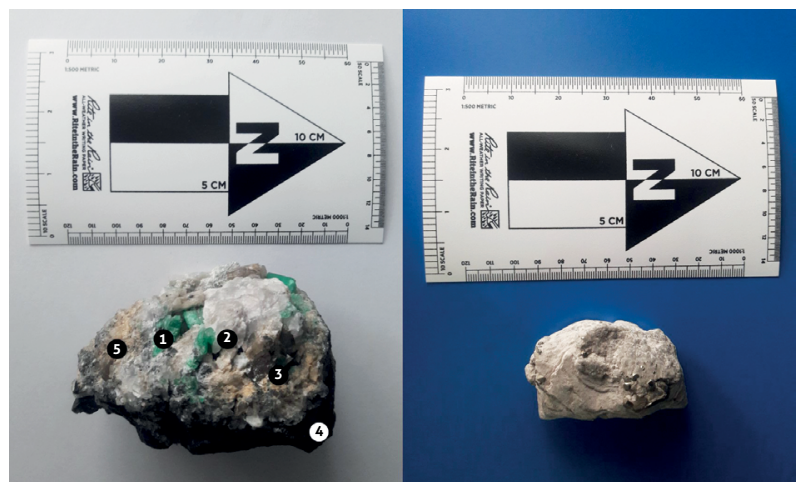

Figura 3. Izquierda: asociación mineral en zona productora. 1) Esmeralda. 2) Calcita fibrosa. 3) Cuarzo. 4) Roca encajante lutítica negra carbonosa. 5) Dolomita y carbonatos de tierras raras. Origen de la muestra: Coscuez (Boyacá). Derecha: albitización en lutitas carbonosas con cristales de pirita. Origen de la muestra: Coscuez (Boyacá)

Fuente: autor

El aporte de elementos traza, como Cr y V, a los fluidos hidrotermales desde la roca encajante y su movilidad a través de la columna estratigráfica no permiten identificar los niveles exactos y las concentraciones necesarias de dichos elementos para la generación de gemas de buena calidad.

Desde el punto de vista estructural, Ujueta (1992) postula lineamientos de orientación NW-SE conocidos como lineamiento de Muzo, al occidente, y lineamiento de Gachalá, al oriente, que controlan la presencia de la mineralización. Existe una relación directa entre las zonas mineralizadas y las estructuras regionales, como la falla del río Minero, los sinclinales de Muzo, Santa Elena, Otanche y Coscuez, y los anticlinales de La Chapa, y aquellos presentes a escala local (Mendoza Parada, 1996).

El factor estructural es un ítem determinante como facilitador del emplazamiento de los fluidos ascendentes mineralizados. El fallamiento y los pliegues a escala macro y micro se convierten en el segundo parámetro de análisis local. La dirección preferencial de las mineralizaciones en Muzo, Quípama y Coscuez, zonas de interés para el presente trabajo, corresponden a orientaciones $\mathrm{N} 40^{\circ} \mathrm{W}$ y N $10^{\circ} \mathrm{E}$, correspondientes a direcciones de esfuerzo máximo $\mathrm{N} 19^{\circ} \pm 10^{\circ} \mathrm{E}$, causante de las fracturas de relajación mineralizadas con dirección preferencial $\mathrm{N} 50^{\circ} \mathrm{W}$ y N80 $\mathrm{E}$ (Mendoza Parada, 1996).

En el aspecto geoquímico y mineralógico se debe analizar el comportamiento de la precipitación de Be como consecuencia de su enriquecimiento por procesos de albitización, posiblemente por pegmatización de los mine- rales en su precipitación o removilización a partir de rocas graníticas y redeposición de los estados finales posmagmáticos (Mendoza Parada, 1996). En la zona de trabajo no están cartografiados cuerpos ígneos de tipo granítico que puedan aportar Be, y aquellos que están reseñados en zonas relativamente contiguas no tienen la temporalidad adecuada que indique que este proceso pueda presentarse. Si bien la albitización está presente en todos los casos de éxito en la exploración esmeraldífera del occidente de Boyacá, no es un indicador único, ya que los procesos metasomáticos provenientes del hidrotermalismo son comunes en la zona, incluso en áreas no productivas.

De forma anómala, el descubrimiento denominado La Pelanga, en la mina de Muzo, litológicamente ubicada en la parte basal de la formación Capotes, suprayacente a la formación Muzo y conformada por lutitas silíceas, indica la movilidad de los fluidos hidrotermales y el arrastre de elementos a niveles superiores, cuya precipitación se produjo por factores eminentemente físicos, como temperatura y presión.

Las variables litoestratigráficas, geoquímicas y estructurales se deben cumplir en su totalidad para que ocurra la precipitación de los fluidos hidrotermales y la formación de los cristales de esmeralda, y de hecho están presentes en el área de estudio. No obstante, esta favorabilidad, la litología, la geomorfología y el clima del área favorecen la generación de una cobertura vegetal abundante que enmascaran las estructuras y no exponen las unidades de roca. Por tales motivos, la identificación de nuevos prospectos se ha restringido históricamente a zonas aledañas a aquellas ya conocidas.

\section{5. Área de estudio}

El área de estudio propuesta se encuentra enmarcada en un polígono de coordenadas $5^{\circ} 38^{\prime} 40,02^{\prime \prime} \mathrm{N}$ a $5^{\circ} 28^{\prime} 18,91^{\prime \prime} \mathrm{N}$ y $-74^{\circ} 12^{\prime} 27,88^{\prime \prime} \mathrm{W}$ a $-74^{\circ} 3^{\prime} 25,88^{\prime \prime} \mathrm{W}$, que comprende los municipios de San Pablo de Borbur, Muzo, Quípama y Maripí, en el occidente del departamento de Boyacá (figura 4).

La zona se caracteriza por un fuerte contraste entre terrenos escarpados de origen estructural y suaves ondulaciones en las zonas más altas por la litología presente. La temperatura oscila entre los 20 y $30^{\circ} \mathrm{C}$, y las alturas, entre los 450 y los 850 m.s.n.m.

La zona en general presenta dos temporadas lluviosas de poca intensidad: la primera, de enero a marzo, y 


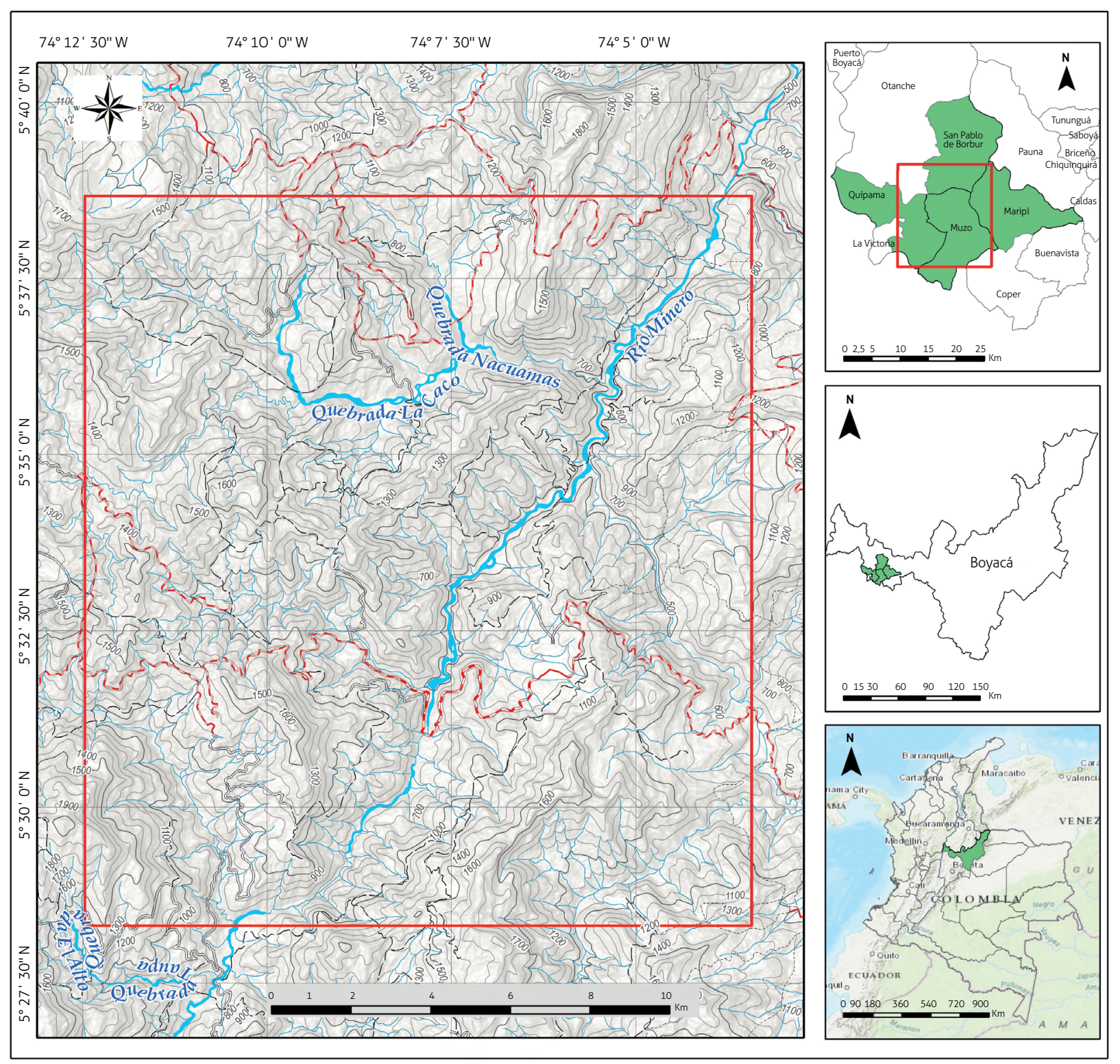

Figura 4. Localización del área de estudio

Fuente: autor

la segunda, de octubre a diciembre. En 2016 se registró una precipitación media de $60 \mathrm{~mm}$ de lluvia anual, con máximos de $330 \mathrm{~mm}$ en octubre (Geoportal IDEAM, s.f.).

\section{Materiales y métodos}

Para llevar a cabo una zonificación de áreas potenciales para la exploración detallada de esmeraldas mediante técnicas de percepción remota en la región de Muzo y
Coscuez, en el departamento de Boyacá, se estructuró un diagrama de flujo que permitiera el diseño y prueba de una metodología que cumpliese ese objetivo (figura 5).

El satélite Sentinel-2 está provisto de una cámara multiespectral que captura una imagen de $290 \mathrm{~km}$ de ancho, con intervalos de longitud de onda desde $490 \mathrm{~nm}$ hasta $2.190 \mathrm{~nm}$ en sus 13 bandas (European Spatial Agency, 2017), obtiene imágenes con resoluciones de 60, 20 y 10 $\mathrm{m} /$ pixel y 450.000 píxeles, lo que permite realizar análisis multiespectrales enfocados en a la geobotánica. 


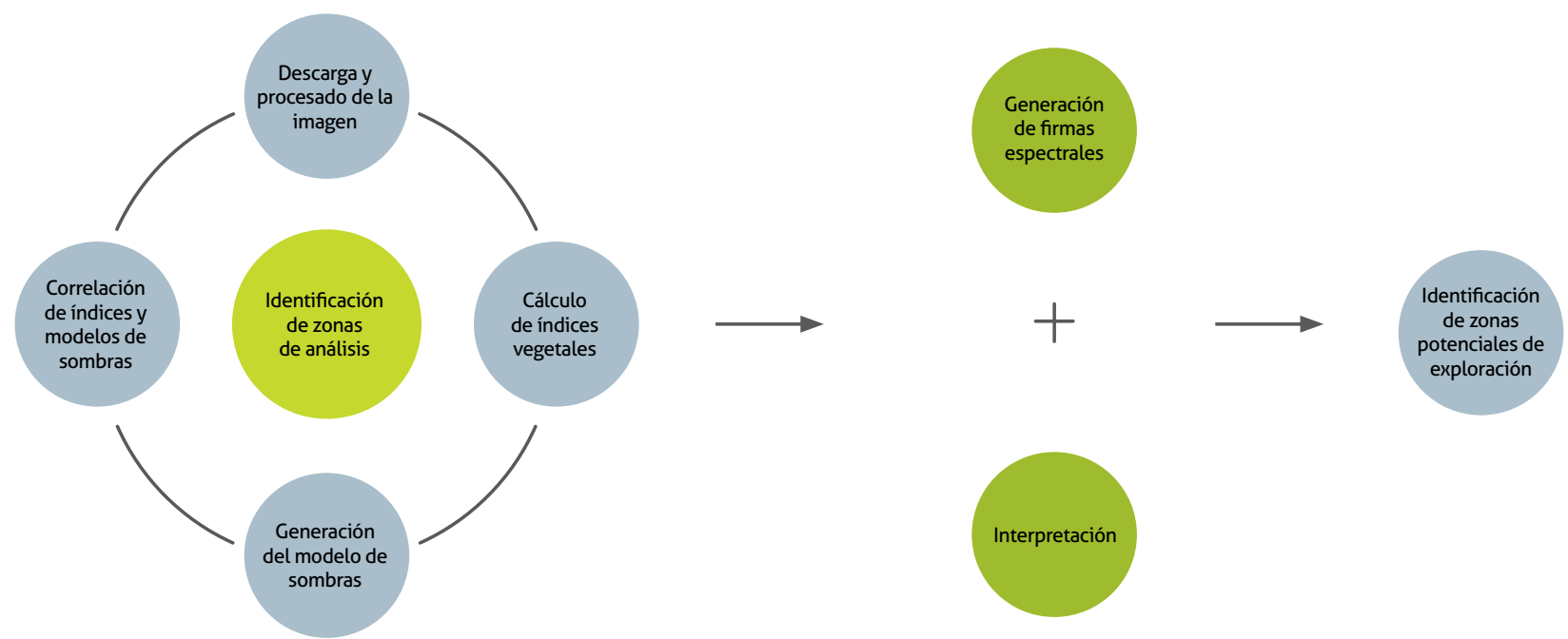

Figura 5. Metodología de trabajo utilizada.

Fuente: autor

Se escogió una imagen del satélite Sentinel-2A, ya que permite el análisis de los diferentes índices que se van a utilizar, su cobertura global y la calidad de las imágenes ópticas a través de su cámara hiperespectral de alta resolución. Se calculó una cobertura de nubes en el área de trabajo menor del $2 \%$. La imagen seleccionada está codificada como S2A_MSIL2A_20170901T152641_N0205_ R025_T18NWM_20170901T152638.

Se realizó la corrección atmosférica mediante el algoritmo Sen2Cor en el software SNAP, que la Agencia Espacial Europea (ESA) distribuye libremente.

Para el modelo digital de terreno (MDT) se utilizó el satélite de acceso gratuito ALOS-PALSAR, con resolución de $12 \mathrm{~m}$, y el procesamiento de la información se realizó por medio del software SNAP.

Se han utilizado, en la medida de lo posible, recursos gratuitos y software libre con el objetivo de abrir la posibilidad de que análisis posteriores por esta metodología no incurran en elevados costos en imágenes y software.

Inicialmente, se interpretó el MDT disponible desde cuatro posiciones de iluminación en azimut $\left(0^{\circ}, 90^{\circ}, 180^{\circ}\right.$ y $270^{\circ}$ ), con un ángulo de inclinación de $70^{\circ}$, escogido en relación con la topografía abrupta del área de trabajo (figura 6). Esta técnica permite observar los rasgos estructurales, en este caso, lineamientos, simulando diferentes posiciones del observador. La generación de esta superficie hipotética que representa el terreno permite simular la proyección de una fuente luminosa desde todos los puntos de vista del observador.

El análisis del modelo de sombras busca identificar los lineamientos naturales como una expresión de fracturas en la superficie en forma de alineamientos de topografía y drenaje, tendencias lineales en vegetación y truncamiento de las secuencias litológicas. Así, se parte de la necesidad de buscar correlaciones claras entre los lineamientos detectados y los resultados obtenidos con los índices de vegetación escogidos.

El índice NDVI es el más frecuentemente utilizado, debido a que una vegetación fotosintéticamente activa presenta, entre sus principales características espectrales, una intensa absorción de radiación en longitudes de onda del rojo visible, por clorofila, y una intensa reflexión de radiación del infrarrojo cercano debido a la estructura foliar (Souza Filho et al., 2008).

Se tienen disponibles índices de vegetación (GNDVI, IPVI, IRED, MSAVI 2, NDI 45, MTCI, NDVI, PVI, PSSRA, REIP, RVI, SAVI, TSAVI, TNDVI, WDV), con el fin de obtener un parámetro de comparación eficiente entre los lineamientos obtenidos mediante la interpretación del modelo de sombras y el resultado de los mismos. Se procesaron los quince índices, de los cuales se obtuvo una mejor correlación con respecto al análisis de lineamientos naturales realizado con el modelo de sombras (tabla 1) en NDVI, GNDVI e IPVI (figura 7). 


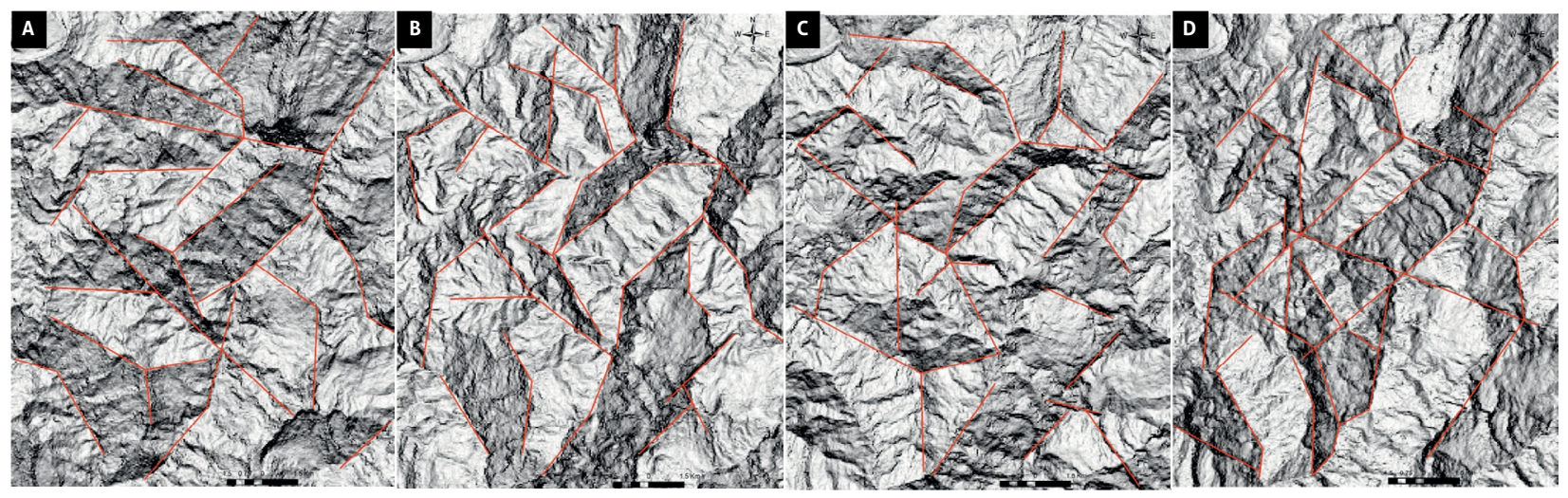

Figura 6. Análisis del modelo de sombras. A) Sombreado $0^{\circ} / 70^{\circ}$. B) Sombreado $90^{\circ} / 70^{\circ}$. C) Sombreado $180^{\circ} / 70^{\circ}$. D) Sombreado $270^{\circ} / 70^{\circ}$. Fuente: autor

Tabla 1. Características de los índices escogidos

\begin{tabular}{|c|c|c|}
\hline Índice & Nombre & Características \\
\hline NDVI & $\begin{array}{l}\text { Índice de vegetación de diferencia } \\
\text { normalizada }\end{array}$ & $\begin{array}{l}\text { Explora la vitalidad de la vegetación en la superficie de la tierra, minimiza } \\
\text { efectos topográficos. Los valores arrojados por dicho índice también oscilan } \\
\text { entre }-1 \text { y } 1 \text {. Valores entre }-1 \text { y } 0 \text { están asociados a la presencia de agua o suelo } \\
\text { desnudo. Se obtiene mediante esta fórmula: } \\
\qquad \text { NDVI = (NIR - RED) / (NIR + RED) }\end{array}$ \\
\hline GNDVI & $\begin{array}{l}\text { Índice de vegetación de diferencia } \\
\text { normalizada verde }\end{array}$ & $\begin{array}{l}\text { El uso de banda espectral verde es más eficiente que la banda espectral roja } \\
\text { para discriminar el nitrógeno. Los valores arrojados por dicho índice también } \\
\text { oscilan entre }-1 \text { y } 1 \text {. Valores entre - } 1 \text { y } 0 \text { están asociados a la presencia de agua } \\
\text { o suelo desnudo. Se obtiene mediante esta fórmula: } \\
\qquad \text { GNDVI = (NIR - GREEN) / (NDVI + GREEN) }\end{array}$ \\
\hline IPVI & $\begin{array}{l}\text { Índice de vegetación porcentual } \\
\text { infrarrojo }\end{array}$ & $\begin{array}{l}\text { Elimina la extrañeza conceptual de los valores negativos de los índices de } \\
\text { vegetación. Por ello es funcionalmente equivalente al NDVI, pero solamente en } \\
\text { el rango de valores entre } 0 \text { y } 1 \text {. Se calcula con esta fórmula: } \\
\qquad I P V I=1 / 2 *(N D V \mid+1)\end{array}$ \\
\hline
\end{tabular}

Fuente: autor
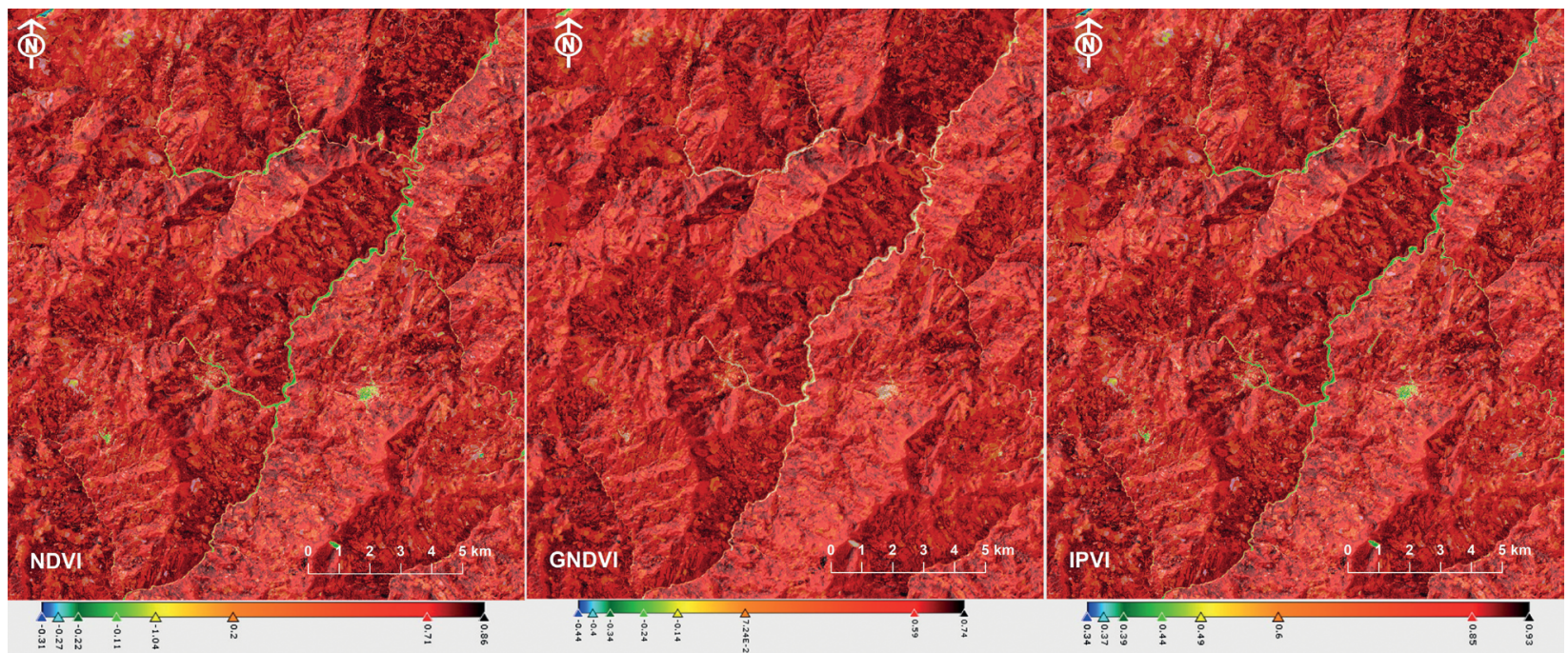

Figura 7. Resultados del cálculo de índices de vegetación NDVI, GNDVI y IPVI.

Fuente: autor 
Para la interpretación se parte de la comparación de la respuesta espectral de puntos conocidos (Prol y Ruiz, 1995). La zona con vegetación sana, en verde, corresponde al comportamiento teórico esperado. Por su parte, la vegetación estresada, azul, se tomó en la zona de la mina de Muzo, y se observa un comportamiento similar al teórico esperado. De igual manera, se obtuvo un espectro de nubes, concreto (zona urbana), tanto del casco urbano de Muzo como de Quípama, con el fin de diferenciarlas efectivamente en el momento del análisis final. Este proceso es fundamental, en la medida en que posibilita encontrar rasgos comunes en las zonas ya conocidas de explotación esmeraldífera, por lo cual pueden ser consideradas un patrón que puede tenerse en cuenta en la posterior elección de las zonas de interés (figura 8).

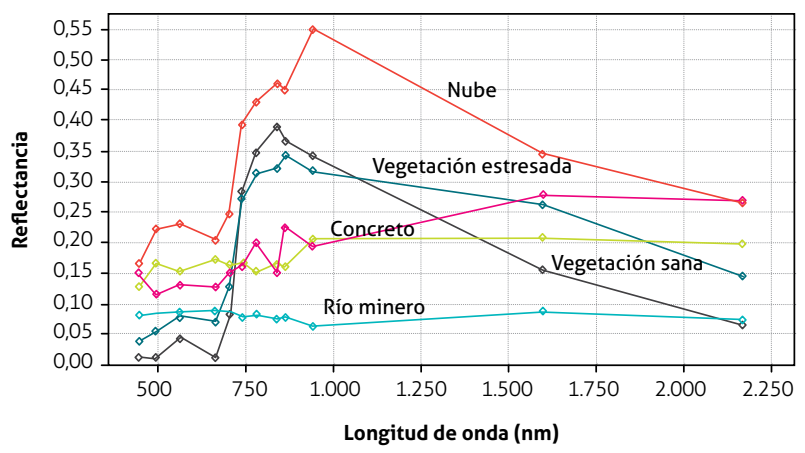

Figura 8. Patronaje de las firmas espectrales de los diferentes materiales con respecto a la vegetación.

Fuente: autor

Teniendo en cuenta este análisis comparativo se seleccionaron líneas a las que se les realizó el análisis espectral independiente, desde el centro de la zona albitizada hacia el exterior (figura 9). La elección de un análisis espectral bidireccional desde un centro, en la mina de Muzo, se basa en la hipótesis de que las mayores concentraciones de elementos están hacia el centro de la mineralización. Para el caso de Coscuez, se plantea únicamente la dirección E-W, en razón de las características estructurales del área. Para la mina La Pita se plantean dos direcciones perpendiculares, evitando la zona de influencia de la falla del río Minero y el posible sesgo de mineralizaciones producidas por este rasgo estructural.

$\mathrm{El}$ análisis posterior de respuestas espectrales de las zonas alteradas parte de la elección de píxeles en dirección centro hacia el exterior que permitan identificar la respuesta de la vegetación a la alteración y tener un panorama completo desde el centro del sector patrón y de la zona elegida.

\section{ANÁLISIS DE RESULtAdos}

Los índices de vegetación son una herramienta eficaz para la interpretación de imágenes satelitales de zonas con una cobertura vegetal densa, ya que es posible diferenciar áreas con una vegetación estresada como respuesta a las condiciones específicas del suelo. La presencia de las zonas albitizadas se interpretó como una respuesta del estado de la vegetación y la presencia de oligoelementos que modifiquen la físico-química del suelo. Se analizaron con base en la banda $8(842 \mathrm{~nm})$ y la banda $4(665 \mathrm{~nm})$ de la imagen Sentinel-2 seleccionada.

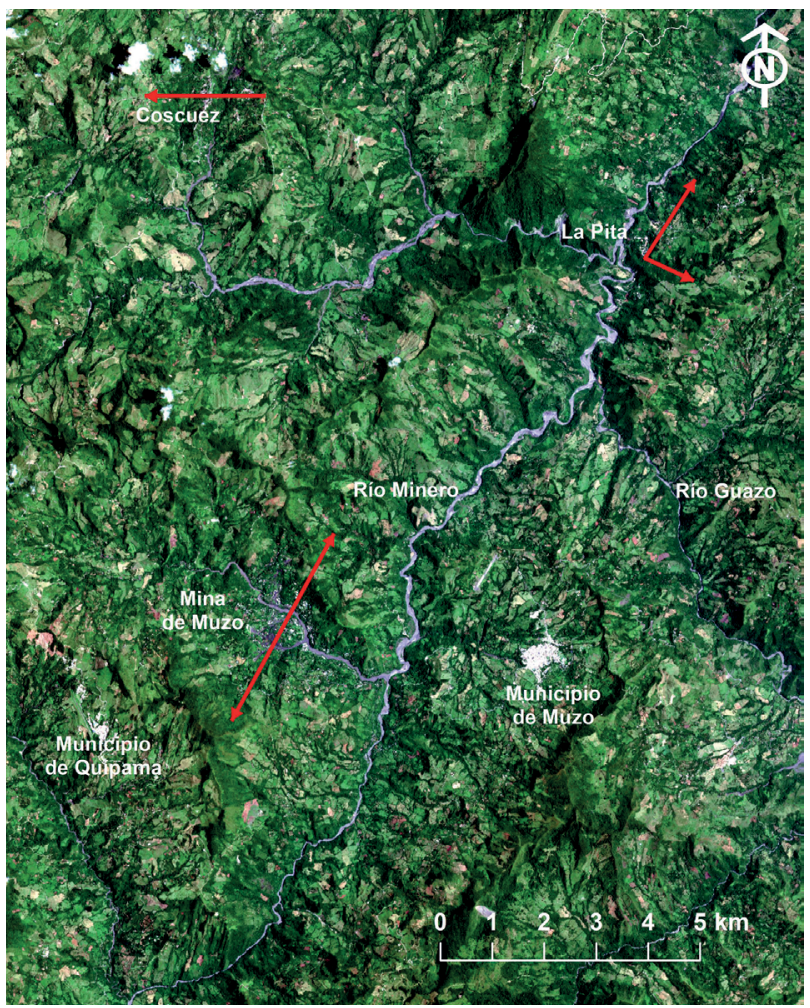

Figura 9. Líneas de evaluación de los índices espectrales seleccionados. Fuente: autor

El patrón de interpretación se llevó a cabo en las tres mineralizaciones conocidas y que han sido históricamente productivas: mina de Muzo, mina de Coscuez y mina La Pita. Existen varias zonas en las que se puede realizar un análisis espectral siguiendo la misma metodología 


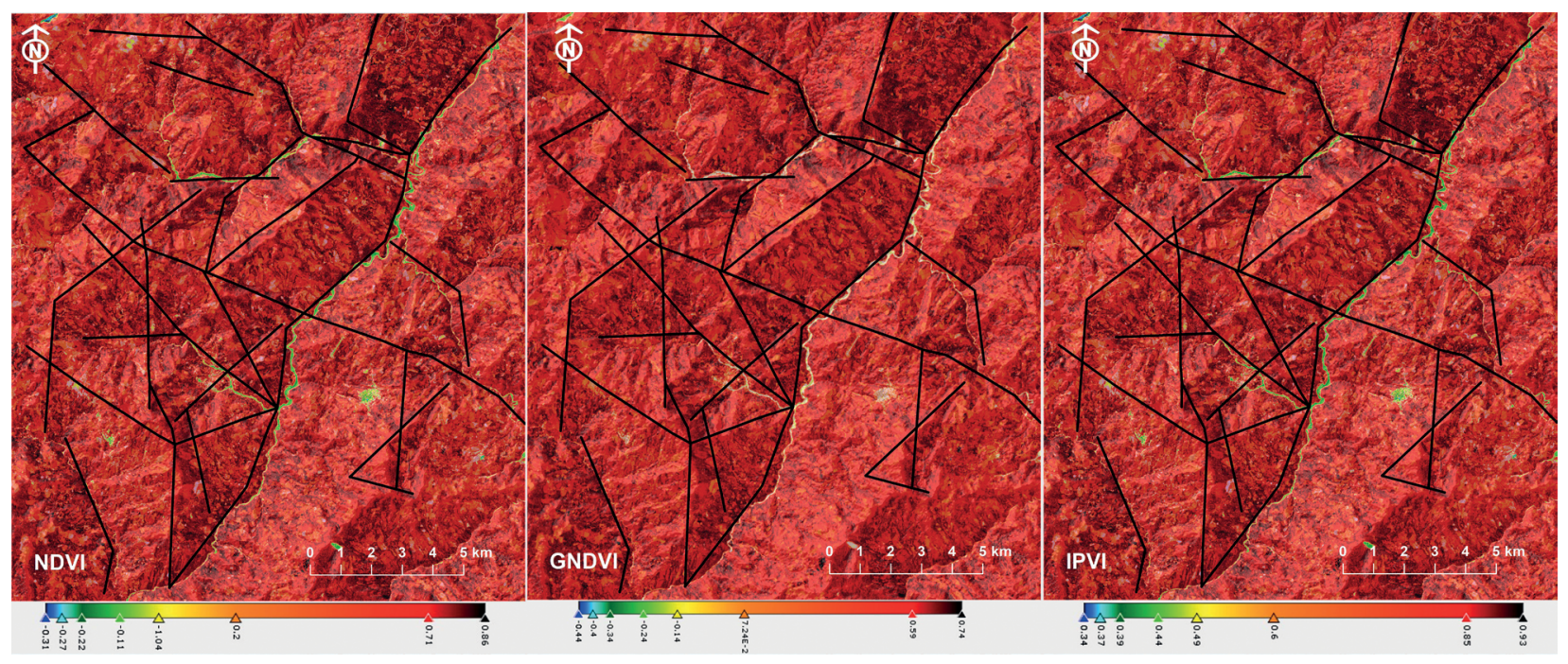

Figura 10. Análisis de lineamientos naturales resultantes cruzados correspondientes a cada uno de los índices de vegetación elegidos. Fuente: autor

planteada. Se escogió la zona más al este de la mina La Pita y al suroeste de la mina de Coscuez, por ser la que mejor coincide con los lineamientos interpretados a partir del modelo de sombras (figura 10) y por presentar mayor anomalía en los tres índices seleccionados (figura 11).

La zona a la que se le realizó el análisis espectral individual de corroboración está situada en dirección $\mathrm{N} 45^{\circ} \mathrm{W}$, entre la mina de La Pita y la mina de Coscuez.

En ella confluye la mayoría de lineamientos naturales identificados en una zona cuyo índice NDVI y GNDVI está en el rango 0 a 0,3 (patronado como zona alterada), y cuyos valores en el índice IPVI estaban en el rango 0 a 0,35 (zona alterada).

La similitud obtenida en los resultados de los tres índices puede simplificar el análisis, y el índice NDVI puede utilizase en posteriores exploraciones.

La zona de la mina de Muzo muestra un muy alto nivel de estrés hacia el interior de la alteración, y presenta menos estrés a medida que se separa del centro de la zona albitizada, nivel determinado por el comportamiento del NIR decreciente hacia la zona central y creciente hacia longitudes de onda más largas (figura 12). Esto puede indicar una forma concéntrica en la zona de alteración, a partir de sitios más altos en concentración de elementos, producto del metasomatismo y una dispersión radial desde este foco.

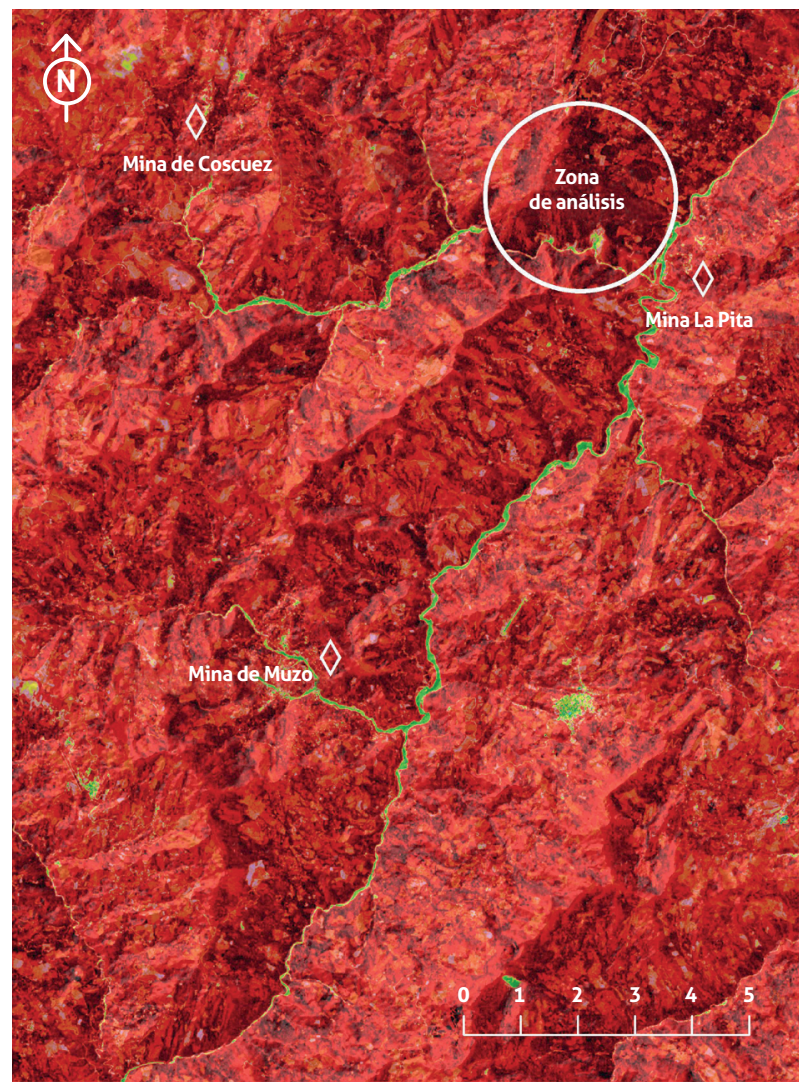

Figura 11. Selección de la zona que será evaluada por análisis espectrales.

Fuente: autor 


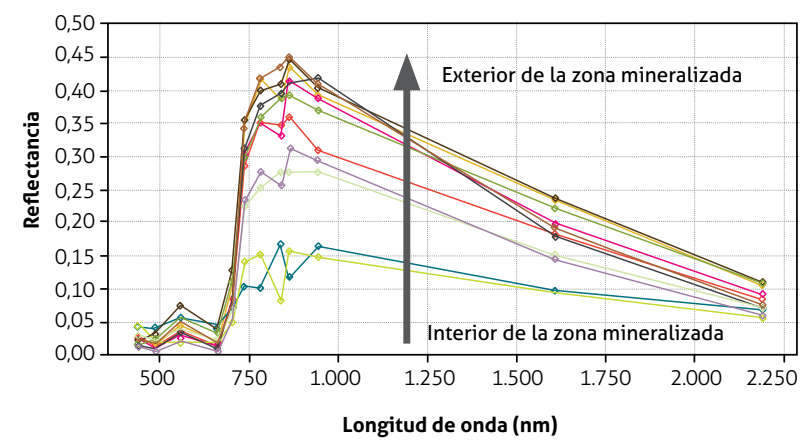

Figura 12. Análisis espectral de la línea de la mina de Muzo

Fuente: autor

La zona de Coscuez presenta un comportamiento similar al de la mina de Muzo, aunque la zona mineralizada podría ser de menor extensión o tener unos niveles de Na menores que la zona de Muzo (figura 13). Si bien se encuentran diferencias en los valores absolutos registrados, el comportamiento del NIR y del rojo es similar, y el estrés en la vegetación tiene parecidas características. El punto Coscuez 3 tiene un comportamiento anómalo en vegetación y se asimila más al tabulado como zona urbana, es decir, pudo haber sido tomado en los campamentos o la zona urbanizada de la vereda.

En la zona de la mina La Pita se tomaron 12 puntos de análisis, ya que es una mina más reciente que Muzo y Coscuez, y por ende, menos estudiada y explorada. Tiene una mayor influencia tectónica por encontrarse a poca distancia de la falla del río Minero, de orden principal, y puede controlar más la mineralización. El comportamiento encontrado se asemeja a los datos arrojados por los dos anteriores análisis (figura 14). Se optó por tomar dos direcciones: una hacia el este, en la misma dirección de los túneles actuales, y otra en dirección noreste, de forma aleatoria, pero alejándose de la falla, con la intención de eliminar el ruido que pudiese generar la falla, por facilitar el ascenso de fluidos hidrotermales. Las características de la vegetación son similares a las anteriores, con una disminución del estrés vegetal hacia la zona exterior de la mineralización.

Finalmente, y tomando como base la mayor correlación existente entre los resultados obtenidos en los trece índices de vegetación, y en particular los obtenidos con el NDVI, el GNDVI y el IPVI, se seleccionó el área de interés. De igual modo, se trazó una línea de la que se obtuvieron las firmas espectrales de los puntos, cuyo resulta- do fue similar en las líneas patrón (figura 15). La zona de transición NIR/RED es anómala en aquellos píxeles cercanos a la zona de lineamiento, y a medida que se separa de la misma, la vegetación presenta una respuesta menos estresada. La aureola de afectación de la vegetación es extensa y puede ser catalogada como una zona de muy alto interés para la exploración detallada de esmeraldas en este sector del occidente de Boyacá.

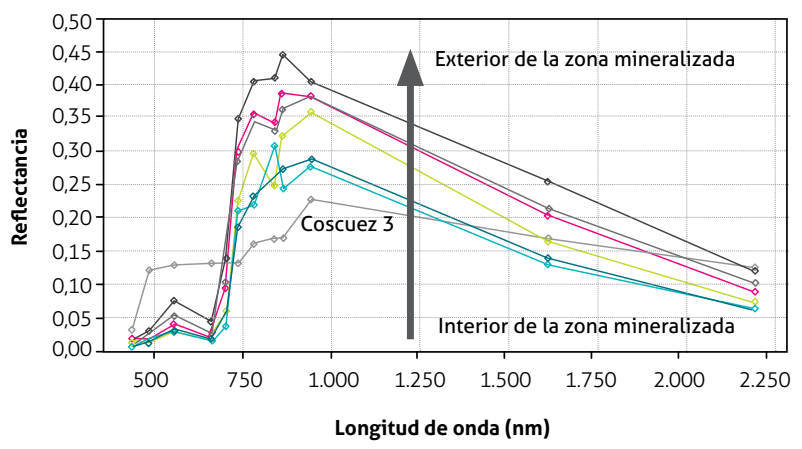

Figura 13. Análisis espectral de la línea de la mina de Coscuez. Fuente: autor

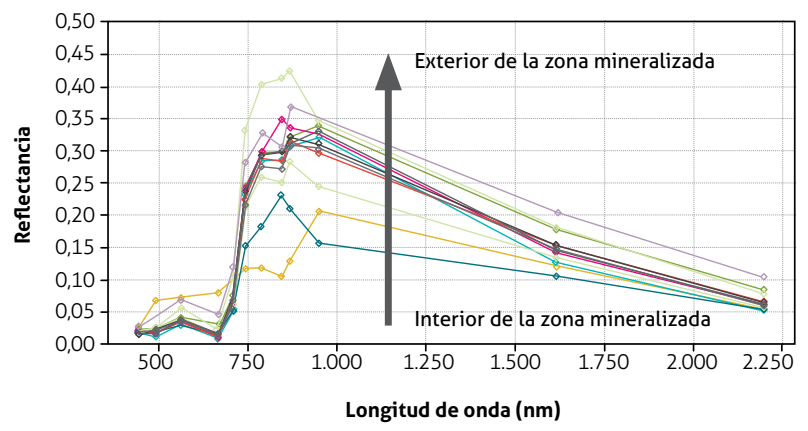

Figura 14. Análisis espectral de las líneas de la mina La Pita Fuente: autor

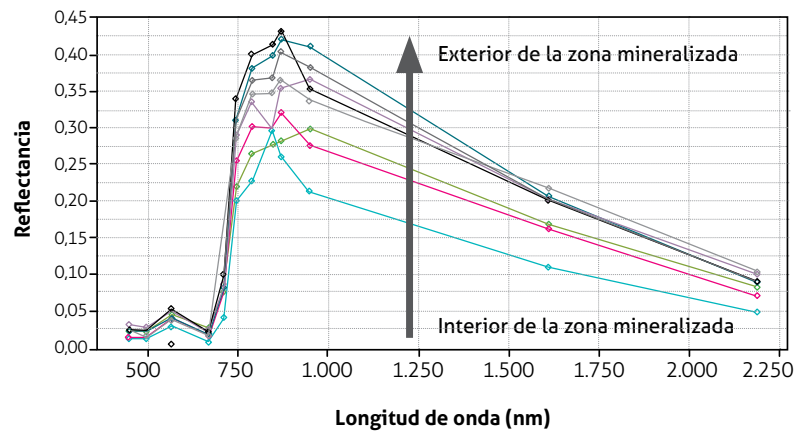

Figura 15. Análisis espectral de las líneas de la zona de interés Fuente: autor 


\section{Conclusiones}

El uso de la metodología de interpretación del modelo de sombras con diferentes ángulos de origen de luminosidad y alto grado de inclinación permitió hacer una evaluación completa de los lineamientos naturales del terreno, como técnica de bajo costo y gran cubrimiento en áreas de cobertura vegetal densa.

Se establecieron lineamientos naturales coincidentes en todas las proyecciones de fuente luminosa, que en muchos casos coinciden con estructuras conocidas, como la falla del río Minero y pliegues cartografiados.

Se encontró que los índices NDVI, IPVI y GNDVI mostraron una mayor correlación entre sus valores patronados como zonas de alteración y los lineamientos naturales determinados con el modelo de sombras.

En las zonas mina de Muzo, mina de Coscuez y mina La Pita, las firmas espectrales obtenidas muestran un comportamiento de aureola, en el que las anomalías geobotánicas están concentradas hacia el centro, y se normalizan hacia el exterior, lo que permitió determinar un patronaje efectivo para la zonificación de áreas no exploradas.

El análisis espectral de las zonas en explotación y el realizado en el área de mayor correlación entre índice vegetal y lineamiento natural arrojó una aureola de estrés concéntrica de la vegetación en todos los casos estudiados, lo que corrobora una relación directa entre la albitización presente en las zonas mineralizadas y la reflectancia de la vegetación.

La metodología desarrollada muestra que es posible identificar zonas de interés en la exploración de esmeraldas mediante la aplicación de técnicas de análisis de anomalías geobotánicas, por medio de índices vegetales y el análisis espectral con software de bajo coste.

\section{Agradecimientos}

El autor desea expresar su más profundo agradecimiento al geólogo Hans Eduardo Morales Böpp y a la geógrafa Milagro Caraballo Pérez, por sus invaluables aportes $\mathrm{y}$ constante asistencia intelectual y técnica.

\section{RefERENCIAS BIBLIOGRÁFICAS}

Biologydictionary.net. (2017). Chlorophyll. Consultado el 8 de septiembre de 2017 en https://biologydictionary.net/chlorophyll/.

Camacho Velasco, A., Vargas-García, C., Rojas-Morales, F., Castillo-Castelblanco, S. y Arguello-Fuentes, H. (2015). Aplicaciones y retos del sensado remoto hiperespectral en la geología colombiana. Revista Facultad de Ingeniería, 24 (40), 17-29. Doi: https://doi.org/10.19053/01211129.3845.

Crosta, A. (1989). Enhancement of Landsat thematic mapper imagery for residual soil mapping in SW minais Gerrain. Proceedings of the 7th (ERIM) Thematic Conference: Remote sensing for exploration geology Calgary. Calgary.

European Spatial Agency (2017). Consultado el 26 de septiembre de 2017 en http://www.esa.int/ESA.

Geoportal IDEAM (s. f.). Consultado el 27 de septiembre de 2017 en https://www.datos.gov.co/Ambiente-y-Desarrollo-Sostenible/Catalogo-Estaciones-IDEAM/ n6vw-vkfe/data.

Heldt, H. W. (1997). Plant biochemistry and molecular biology. Oxford: Oxford Uninversity Press.

Mendoza Parada, J. (1996). Anotaciones geoquímicas para exploración de esmeraldas en la región $\mathrm{Mu}$ zo-Coscuez con base en la relación $\mathrm{Na} / \mathrm{K}$ y elementos traza. Geología Colombiana, 21, 89-98.

Milgrom, L. R. (1997). The colours of life: An introduction to the chemistry of porphyrins and related compounds. Oxford: Oxford University Press.

Prieto, J., González Ramírez, C. A., Román Gutiérrez, A. D. y Prieto García, F. (2009). Contaminación y fitotoxicidad en plantas por metales. Tropical and Subtropical Agroecosystems, 10 (1), 19-44.

Prol Ledesma, R. M. y Ruiz-Armenta, J. R. (1995). Técnicas de procesamiento de imágenes en la exploración de yacimientos minerales de origen hidrotermal. Física de la Tierra, 7, 105-137.

Ross, J. (1981). The radiation regime and architecture of plants stands. Londres: Springer. Doi: https://doi.org/10.1007/978-94-009-8647-3.

Sahuquillo, A., Rigol, A. y Rauret, G. (2003). Overview of the use of leaching extraction tests for risk assessment 
of trace metals in contaminated soils and sediments. Trends in Analytical Chemistry, 22 (3), 152-159. Doi: http://doi.org/10.1016/S0165-9936(03)00303-0.

Singer, M. (2015). Photophosphorylation: The light reactions in photosynthesis. OpenStax CNX. Consultado en https://cnx.org/contents/-CmzvUct@12/The-Light-Dependent-Reactions-of-Photosynthesis.

Souza Filho, C., Augusto, V., Oliveira, W. J. y Lammoglia, T. (2008). Detecção de exsudações de hidrocarbonetos por geobotânica e sensoriamento remoto multi-temporal: estudo de caso no Remanso do Fogo (MG). Revista Brasileira de Geociências, 38 (1, sup. 2), 228-243.

Towers, P. C. y von Martini, A. (2002). Conceptos iniciales sobre teledetección y su aplicación al agro. Buenos Aires: AgriSat.
Ujueta, G. (1992). Lineamientos río Ariari, Bogotá y Gachalá, en los departamentos de Cundinamarca y Meta, Colombia. Revista Academia Colombiana de Ciencias Exactas, Físicas y Naturales, 18 (70), 345-358.

Unidad de Planeación Minero-Energética (2014). Plan Nacional de Desarrollo Minero. Bogotá: Ministerio de Minas y Energía.

Van der Meer, F. (2006). The effectiveness of spectral similarity measures for the analysis of hyperspectral imagery. International Journal of Applied Earth Observation and Geoinformation, 8 (1), 3-17. Doi: https://doi.org/10.1016/j.jag.2005.06.001.

Xue, J. y Su, B. (2017). Significant remote sensing vegetation indices: A review of developments and applications. Journal of Sensors, 2017. Doi: https://doi.org/10.1155/2017/1353691. 